\title{
Phenomena in a Blast Furnace Operated at an Extremely
}

\section{Low Fuel Rate*}

\section{By Shuji KAJIKAWA,** Ryoji YAMAMOTO,** Ryuichi NAKAJIMA,** Sumiyuki KISHIMOTO** and Tsutomu FUKUSHIMA***}

\section{Synopsis}

In order to clarify the various phenomena in a blast furnace and its operational problems at the extremely low fuel rate, Nippon Kokan $K . K$. decided to execute a trial operation in No. 3 blast furnace (inner volume: $3223 \mathrm{~m}^{3}$, blow in; January 1975) at Fukuyama Works.

As a result, a monthly mean fuel rate of $396 \mathrm{~kg} / \mathrm{T}$ was recorded in November 1981. Comparing with the result of the previous test operation in the same furnace (428 kg/T, January 1979), heat requirements at the lower part of the furnace could be much reduced.

Both the high reducibility of sinter and adequate burden distribution control enabled to produce and keep the high shaft gas efficiency of $97.5 \%$.

As the heat flux ratio increased, temperature level at the shaft lowered and the three stages of thermal reserve zones were observed. The level of cohesive zone also lowered and its shape changed from "inverse V" to " $V$ " via " $W$ " shape, furthermore some of the measured results indicated that the melting line would be very close to the raceway. In its transitional period, the burden descent became somewhat unstable, but got well again when the fuel rate reduced to around $400 \mathrm{~kg} / \mathrm{T}$.

\section{Introduction}

From the standpoints of improving process engineering and control techniques of blast furnaces, low fuel rate operation technology is an important problem and trial operations aiming at the lower fuel rate have been carried out recently in several blast furnaces. ${ }^{1-5}$ )

In order to clarify the various phenomena in a blast furnace and various problems concerning the blast furnace operation at an extremely low fuel rate, Nippon Kokan K.K. carried out a test operation in No. 3 Blast Furnace (inner volume; $3223 \mathrm{~m}^{3}$, blow in; Jan. 1975) at Fukuyama Works. As a result, a monthly mean fuel rate of $396 \mathrm{~kg} / \mathrm{T}$ was recorded in Nov. 1981.

In this report, the factors which allowed this low fuel rate to be achieved and the distinctive features of the phenomena observed during the test operation are presented and considered. Based on these results, the major factors which restrict the low fuel rate operation are discussed.

\section{I1. Results of Low Fuel Rate Test Operation}

\section{Operation Results}

Trends in Fukuyama No. 3 Blast Furnace operation before and after the test are shown in Fig. 1. At the beginning of August 1981 its operation was shifted from all-coke to tar-injection, and from that time on the fuel rate was reduced at a considerably rapid rate by increasing the sinter ratio and by switching to a high temperature/low humidity blast.
In parallel with the increase in ore/coke ratio, the coke base was kept at $27 \mathrm{t} / \mathrm{ch}$ until the end of October, then decreased to $24.6 \mathrm{t} / \mathrm{ch}$ for the purpose of improving the thermal state stability.

The furnace condition in November was favorably stable. Particularly in the latter part of November when the reducibility index (R.I.), based on the JIS method, of sintered ore was being maintained at a high level of around $70,{ }^{6}$ the fuel rate could be

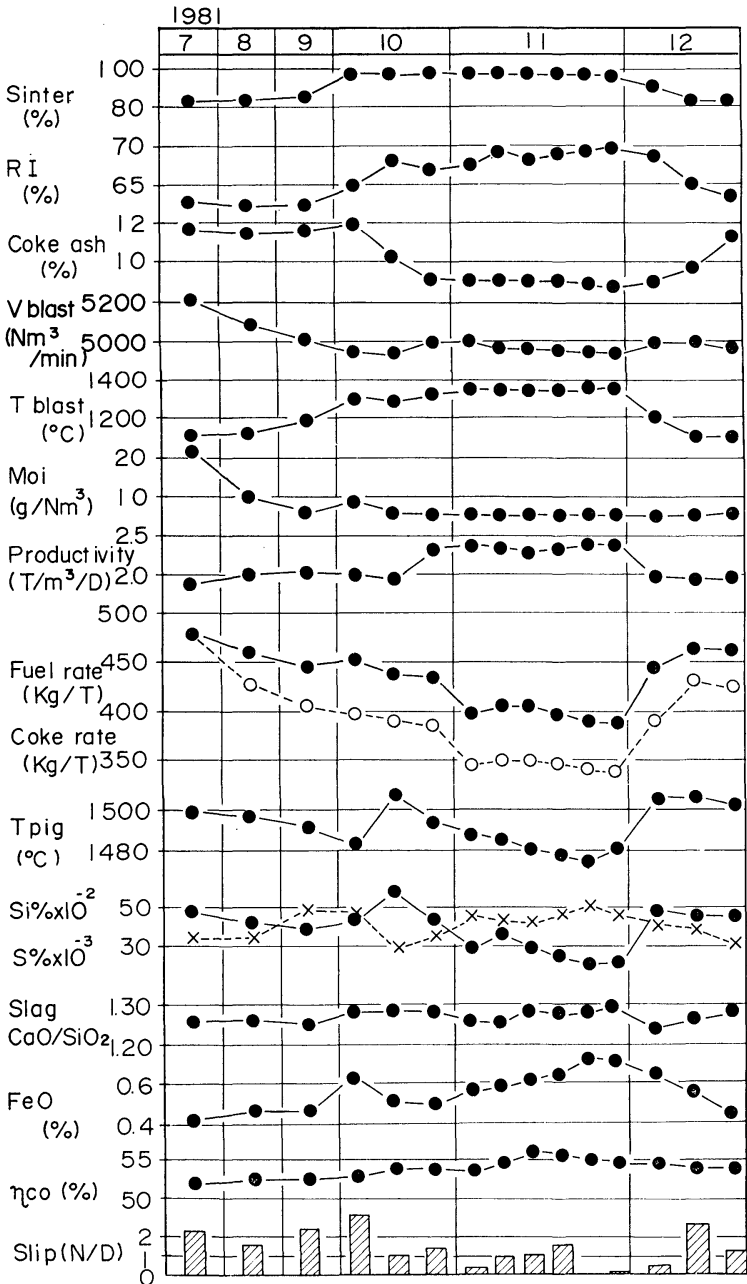

(a) Ordinary operation

(b) Low fuel rate operation

(c) Relation between temperature of reserve zone and heat flux ratio

Fig. 1. Trend of Fukuyama No. 3 BF operation.

* Originally published in Tetsu-to-Hagané, 68 (1982), No. 15, Special Issue on Ironmaking, 2361, in Japanese; Formerly presented to the 103rd ISIJ Meeting, April 1982, S48 and S49, at Tokyo Institute of Technology in Tokyo. English version received September 1, 1982. (C) 1983 ISIJ

** Fukuyama Works, Nippon Kokan K.K., Kokan-cho, Fukuyama 721.

*** Technical Research Center, Nippon Kokan K.K., Minamiwatarida-cho, Kawasaki-ku, Kawasaki 210. 
lowered to the level of $380 \mathrm{~kg} / \mathrm{T}$.

Operation results in November were shown in Table 1. For the purpose of saving the necessary heat in the lower part of furnace, the thermal level of furnace was decreased as low as possible, so that a monthly mean hot metal temperature was $1481^{\circ} \mathrm{C}$ in November, although the temperature target in normal operation was $1505^{\circ} \mathrm{C}$. This necessarily resulted in the poor fluidity of slag and the tapping frequency was compelled to increase remarkably with a view to smooth extracting of slag.

In spite of so high heat flux ratio (solid phase heat flux/gas phase heat flux) of 0.915 at the shaft, the shaft gas efficiency based on the Rist operation diagram was maintained at a high level of $97.5 \%$ $\left(\eta_{\mathrm{co}}: 54.8 \%\right)$ in consequence of both the high ratio of high R.I. sintered ore and the burden distribution control which brought a uniformly high gas utilization through the radial direction.

\section{Factors Contributing to Lowering the Fuel Rate}

Figure 2 indicates a comparison of operation diagrams between the previous result for a low fuel rate at the same furnace (June 1979, $428 \mathrm{~kg} / \mathrm{T}$ ) ${ }^{3)}$ and the result of this time. From the behavior of $(\mathrm{P}$ point in the diagram, it is understood that the main factor contributing to the favorable result was a substantial reduction of necessary heat at the lower part of the furnace. Namely it is represented by the rise of (1) point due to the decrease in the reduced amount of various metalloids including $\mathrm{Si}$ and the rise of (1) point due to the reduction of sensible heat of molten metal and slag and of furnace heat loss.

The carbon balance and heat balance in both periods are compared in the same way in Table 2.

The input heat per ton of hot metal was reduced by about $7 \%$ as compared with that in the previous result. Referring to the items of output heat, top gas sensible heat, molten slag and metal sensible heat and furnace heat loss are remarkably reduced.

Although the gas utilization degree could be kept at a higher level than that of the previous operation, the amount of solution-loss carbon slightly increased due to the considerable reduction of the necessary heat in the lower part of furnace, that is, the rise of (P) point in Fig. 2.

Table 1. Results of the low fuel rate operation.

\begin{tabular}{|c|c|c|c|c|c|c|}
\hline \multicolumn{3}{|c|}{ Blast conditions } & \multicolumn{4}{|c|}{ Production and fuel rate } \\
\hline Blast & $\begin{array}{l}\text { Volume } \\
\text { Press. } \\
\text { Temp. } \\
\text { Moi. }\end{array}$ & $\begin{array}{cl}4952 & \mathrm{Nm} / \mathrm{min} \\
3.59 \mathrm{~kg} / \mathrm{cm}^{2} \\
1353 \quad{ }^{\circ} \mathrm{G} \\
5.6 \mathrm{~g} / \mathrm{Nm}^{3}\end{array}$ & \multirow{2}{*}{\multicolumn{2}{|c|}{$\begin{array}{l}\text { Output } \\
\text { Productivity } \\
\text { Blow off time } \\
\text { Fuel rate } \\
\text { Coke rate } \\
\text { Tar rate }\end{array}$}} & $\begin{array}{c}7636 \\
2.37 \\
0 \\
396.1\end{array}$ & $\begin{array}{l}\mathrm{T} / \text { day } \\
\mathrm{T} / \text { day } / \mathrm{m}^{3} \\
\mathrm{~kg} / \mathrm{T}\end{array}$ \\
\hline \multirow{2}{*}{\multicolumn{2}{|c|}{$\begin{array}{l}\mathrm{O}_{2} \text { enrichment } \\
\text { Top press. } \\
\text { Flame temp. }\end{array}$}} & $\begin{array}{l}0 \% \\
2.48 \mathrm{~kg} / \mathrm{cm}^{2}\end{array}$ & & & $\begin{array}{r}354.0 \\
42.1\end{array}$ & $\begin{array}{l}\mathrm{kg} / \mathrm{T} \\
\mathrm{kg} / \mathrm{T}\end{array}$ \\
\hline & & $2533 \quad{ }^{\circ} \mathrm{C}$ & \multicolumn{4}{|c|}{ Hot metal and slag } \\
\hline \multicolumn{3}{|c|}{ Burden conditions } & \multirow[b]{2}{*}{$\begin{array}{l}\text { Hot } \\
\text { metal }\end{array}$} & Temp. & 1481 & ${ }^{\circ} \mathrm{C}$ \\
\hline \multicolumn{2}{|c|}{$\begin{array}{l}\text { Sinter ratio } \\
\text { Miscellaneous } \\
\text { Flux }\end{array}$} & $\begin{array}{rl}96.6 & \% \\
3.4 & \% \\
1.9 & \mathrm{~kg} / \mathrm{T}\end{array}$ & & $\begin{array}{l}\mathrm{Si} \\
\mathrm{S} \\
\mathrm{Mn} \\
\mathrm{P}\end{array}$ & $\begin{array}{l}0.27 \\
0.045 \\
0.43 \\
0.098\end{array}$ & $\begin{array}{r}\% \\
\% \\
\% \\
\%\end{array}$ \\
\hline Coke & $\begin{array}{l}D I_{15}^{30} \\
\text { Mean size } \\
\text { Ash } \\
\mathrm{S}\end{array}$ & $\begin{array}{l}92.9 \\
52.3 \mathrm{~mm} \\
9.01 \% \\
0.78 \%\end{array}$ & \multirow[t]{2}{*}{ Slag } & $\begin{array}{l}\mathrm{CaO} / \mathrm{SiO}_{2} \\
\mathrm{Al}_{2} \mathrm{O}_{3} \\
\mathrm{MgO} \\
\mathrm{FeO}\end{array}$ & $\begin{array}{c}1.28 \\
14.0 \\
7.3 \\
0.64\end{array}$ & $\begin{array}{l}\% \\
\% \\
\%\end{array}$ \\
\hline \multirow{4}{*}{ Sinter } & $T I(S I)$ & $65.2(90.5)$ & & $\mathrm{S}$ & 1.09 & $\%$ \\
\hline & $\mathrm{SiO}_{2}$ & $5.01 \%$ & \multicolumn{2}{|c|}{ Desulfurization } & 84.9 & $\%$ \\
\hline & $\mathrm{FeO}$ & $4.61 \%$ & \multicolumn{4}{|c|}{ Top gas } \\
\hline & $\begin{array}{l}R D I \\
R I\end{array}$ & $\begin{array}{l}1.43 \% \\
36.9 \\
68.9\end{array}$ & \multirow{2}{*}{\multicolumn{2}{|c|}{$\begin{array}{l}\text { Temperature } \\
\mathrm{CO} \\
\mathrm{CO}_{2} \\
\mathrm{H}_{2}\end{array}$}} & $\begin{array}{l}73 \\
20.2 \\
24.5\end{array}$ & $\begin{array}{l}{ }^{\circ} \mathrm{C} \\
\% \\
\%\end{array}$ \\
\hline Sla & & $274 \quad \mathrm{~kg} / \mathrm{T}$ & & & 1.7 & $\%$ \\
\hline \multicolumn{3}{|c|}{ Furnace conditions } & \multicolumn{4}{|c|}{ Others } \\
\hline \multirow{4}{*}{\multicolumn{2}{|c|}{$\begin{array}{l}\text { Pressure diff. } \\
\text { Slip } \\
\text { Dust } \\
\sigma_{\mathrm{Si}}\end{array}$}} & \multirow{4}{*}{$\begin{array}{l}1.11 \mathrm{~kg} / \mathrm{cm}^{2} \\
0.7 \mathrm{times} / \text { day } \\
7.7 \mathrm{~kg} / \mathrm{T} \\
0.12 \%\end{array}$} & \multirow{3}{*}{ Shaft } & Gas eff. & 97.5 & $\%$ \\
\hline & & & & $\eta_{\mathrm{CO}}$ & 54.8 & $\%$ \\
\hline & & & & $\eta_{\mathrm{H}_{2}}$ & 58.6 & $\%$ \\
\hline & & & \multirow{2}{*}{\multicolumn{2}{|c|}{$\begin{array}{l}\text { Heat flux ratio } \\
\text { No. of tappings }\end{array}$}} & \multicolumn{2}{|c|}{0.915} \\
\hline & & & & & 17.4 & taps/day \\
\hline
\end{tabular}




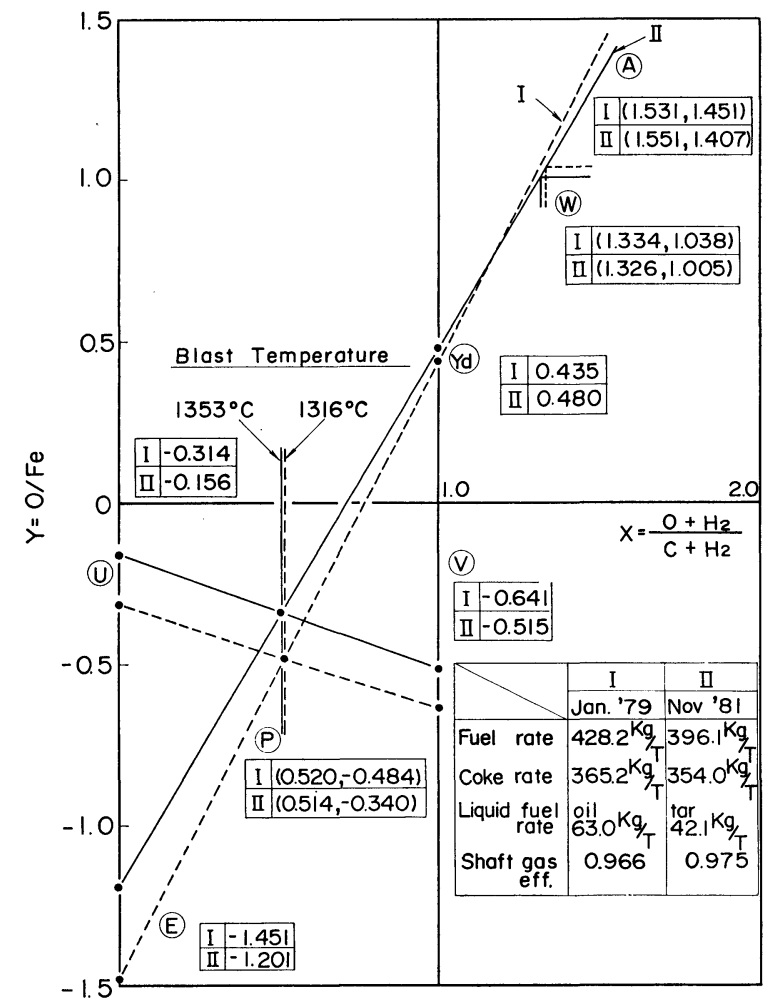

Fig. 2. Comparison of low fuel rate operation using RISTdiagram.

Table 2. Comparison of carbon and heat balance.

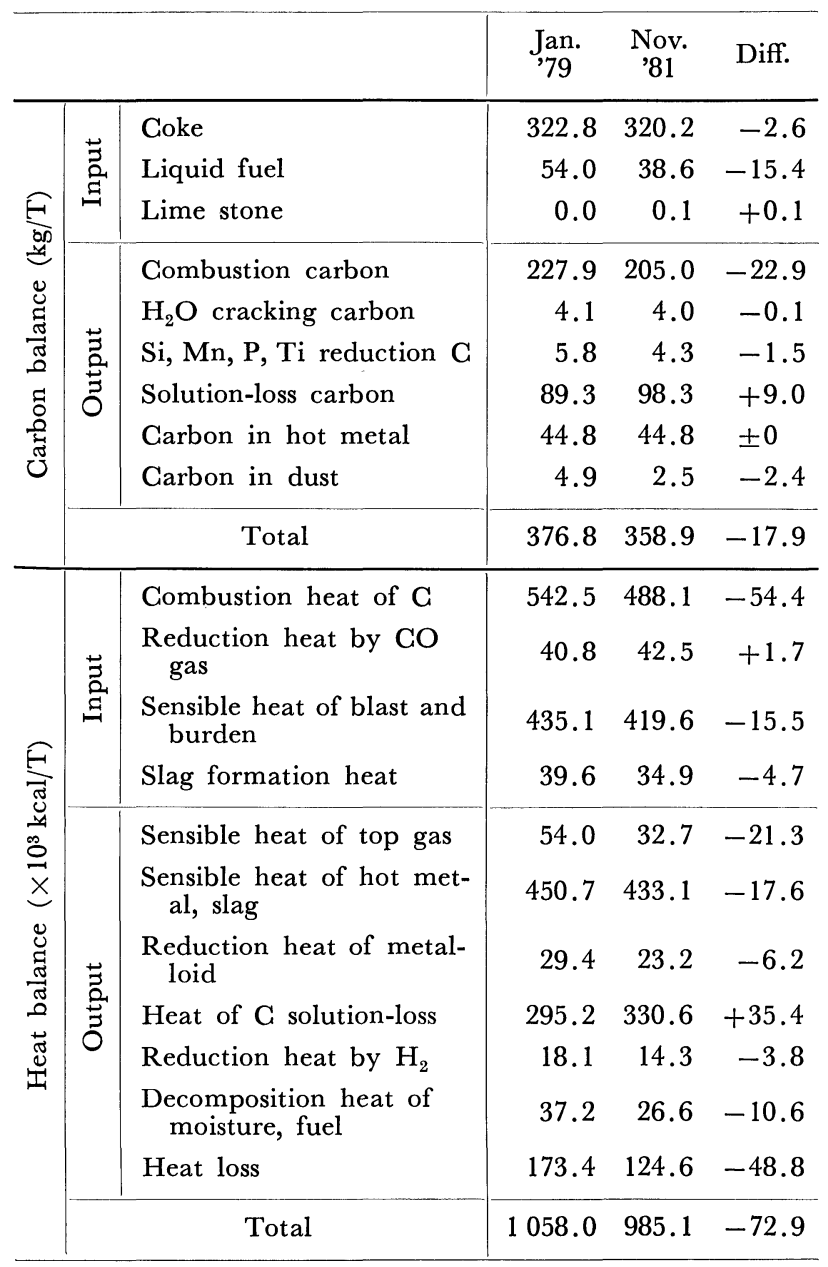

The essential hindrances to get further low fuel rate in future seemed to be the reducibility of ore at the small effective zone for its indirect reduction and the fusing capacity of ore layers around the raceway.

\section{Phenomena in the Furnace}

\section{Pressure Distribution in the Furnace}

Pressure loss through the furnace was reduced along with the reduction in the fuel rate, as shown in Fig. 3. The dotted-line in the figure indicates calculated results by the mathematical model ${ }^{7)}$ for a simulation of gas flow in a furnace based on the observed temperature distribution. These figures agree well with those of actual measurement. Namely, the above phenomenon resulted from a decrease in the gas velocity due to the lowering of its temperature, which is mentioned later on, consequently contributing to the stable furnace condition at a high ore/coke ratio.

\section{Temperature Distribution in the Furnace and Progress of Reducing Reaction}

1. Temperature Distribution in the Furnace

In the process of increase in heat flux ratio at the shaft, the vertical temperature profile drastically changed as shown in Fig. 4, where the stagnation of temperature rise was observed at several levels. The relation between the temperature level of stagnation of temperature rise and heat flux ratio is also shown in Fig. 4. These characteristics are summarized in the following 4 points.

(1) The rate of temperature rise at the shaft is very slow, whereas temperature goes up quickly at the lower part of the furnace (Fig. 4 (b)).

(2) The stagnation of temperature rise appears not only at the thermal reserve zone of around $1000{ }^{\circ} \mathrm{C}$ (1st reserve zone) but also at zones of $600 \sim$ $750{ }^{\circ} \mathrm{C}$ (2nd reserve zone) and of $200 \sim 400{ }^{\circ} \mathrm{C}$ (3rd reserve zone) in this order. This tendency is especially conspicuous in the area from the intermediate to the wall side through the furnace radius (Fig. 4 (c)).

(3) As the heat flux ratio increases, 1st and 3rd thermal reserve zones can be detected clearly but the 2nd zone becomes indistinct or disappears (Fig. 4 (c)).

(4) In the central part of the furnace, the thermal reserve zone of around $1000^{\circ} \mathrm{C}$ was held nearly to the dead-man when the heat flux ratio rose to exceedingly high level (Fig. 4 (b)). The factors causing each thermal reserve zone are considered as follows; 1st reserve zone is caused by a change of heat flux ratio due to the solution-loss reaction, 2nd reserve zone is caused by endothermic reaction of $\mathrm{Fe}_{3} \mathrm{O}_{4}$ to $\mathrm{FeO}$, and 3rd reserve zone resulted from the facts that the difference of temperature between solid phase and gas phase is slight and the ascending gas drifts toward the central side at the portion close to the stock surface.

As to the reasons for the disappearance of 2 nd thermal reserve zone at the high heat flux ratio 
mentioned in (3), further study will be necessary. However, it is assumed to be linked with the behavior of the reducing reaction given in the following paragraph. As for the tendency of temperature rise in the center of a furnace mentioned in (4), it corresponds to the fact that the amount of ore was increased in this area in order to improve the overall gas utilization and gas flow toward the top of the dead-man was much reduced, along with the change of infurnace state which will be discussed later.

\section{Progress of Reducing Reaction}

The delay in the temperature rise at the shaft slows down inevitably the rate of reducing reaction, which raises necessarily the amount of solution loss carbon and lowers the shaft gas efficiency.

In order to prevent the above, sintered ore of high reducibility must be indespensable for the low fuel rate operation.

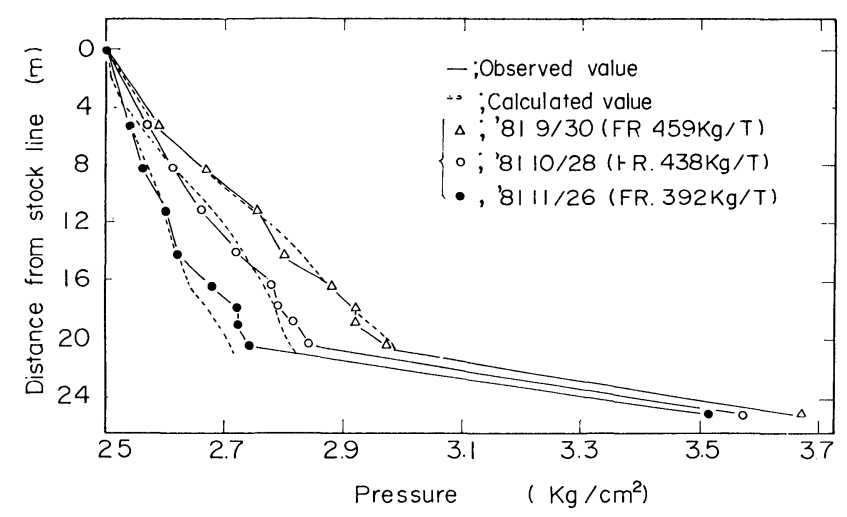

Fig. 3. Transition of the pressure distribution pattern.
The contribution of reducibility of sintered ore which was used in the test operation is shown in Fig. 5, as relations of heat flux ratio related to fuel

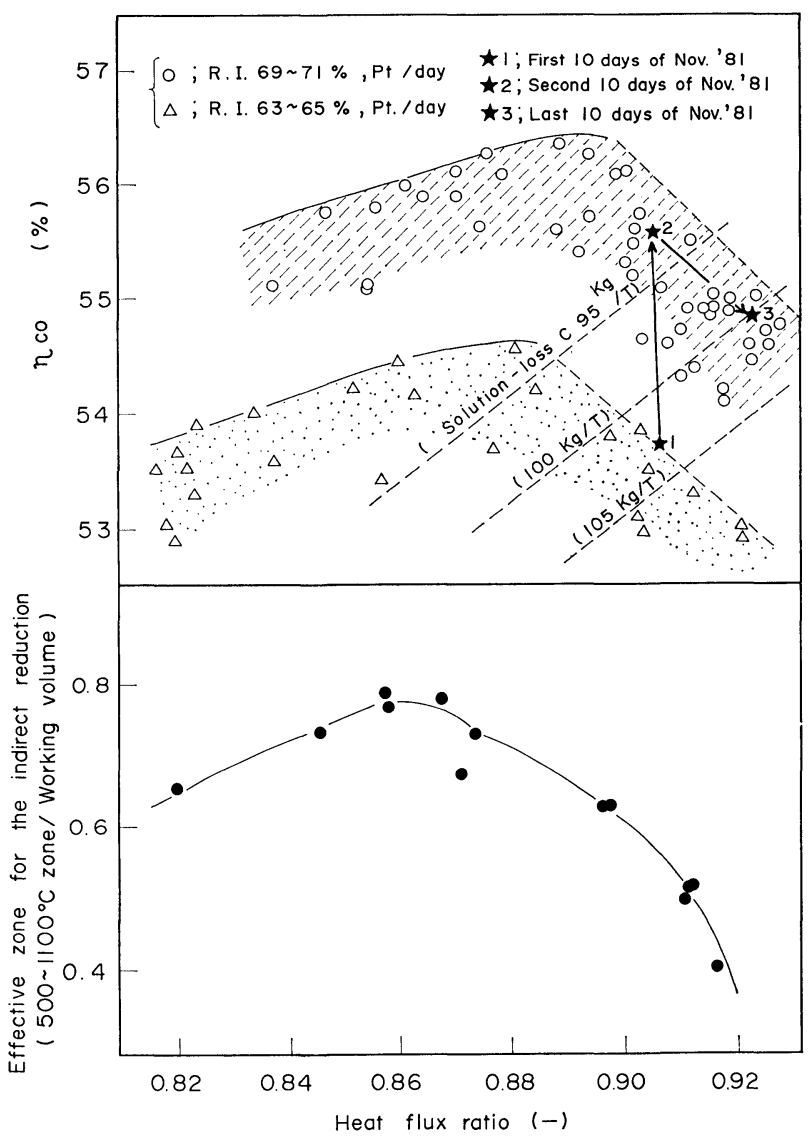

Fig. 5. Relation between $\eta_{\mathrm{CO}}$, effective indirect reduction zone and heat flux ratio.

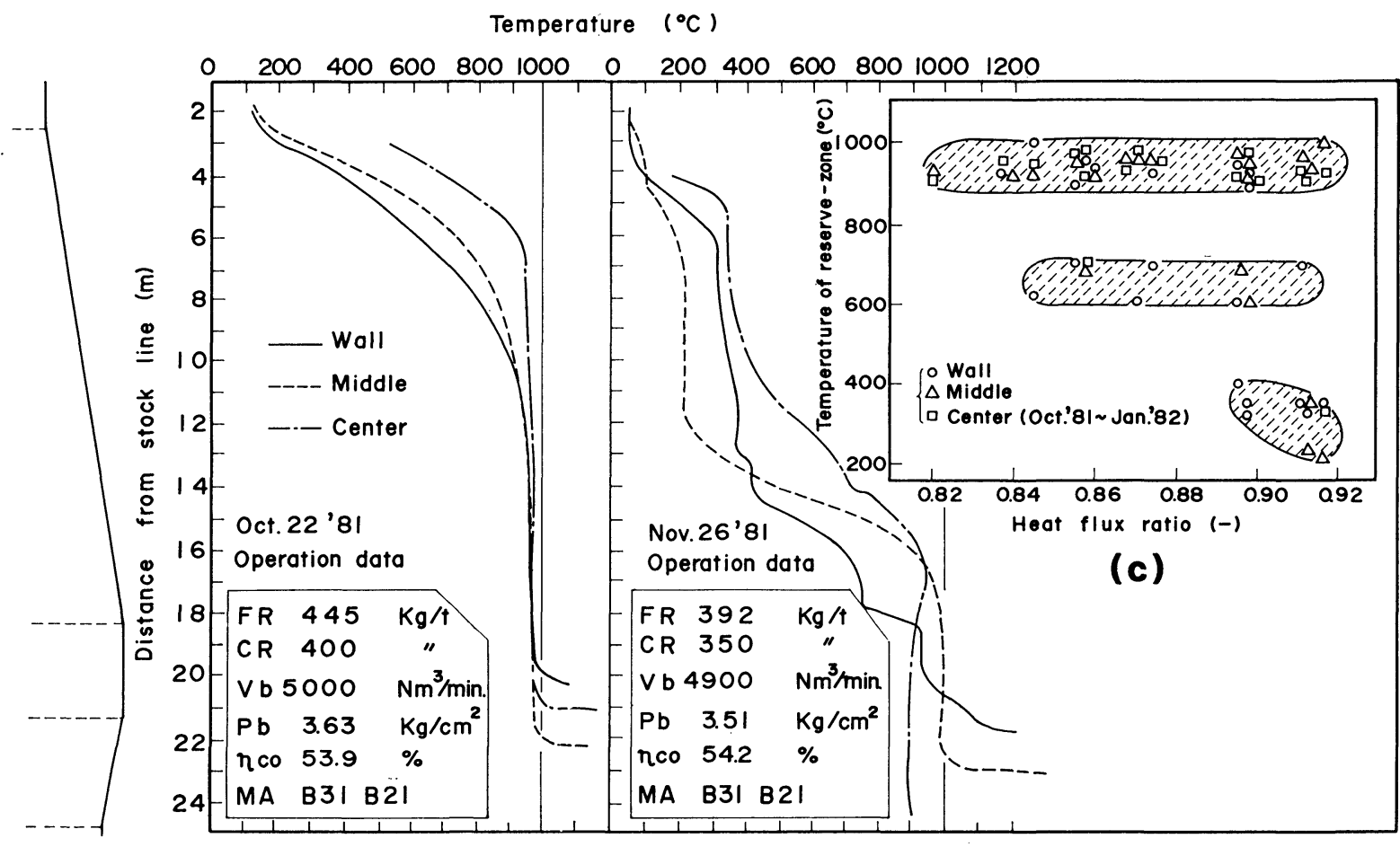

(a)

(b)

Fig. 4. Transition of the temperature distribution pattern. 
rate to the effective volume of the indirect reduction zone and shaft gas efficiency.

In the process of fuel rate reduction, that is, heat flux ratio rising, the level of $\eta_{\mathrm{co}}$ was improved due to both decrease in reducing gas amount per ton of ore and increase in the effective indirect reduction zone, which corresponds to lowering of the cohesive zone level.

When the heat flux ratio gets excessively high, however, $\eta_{\mathrm{co}}$ becomes worse again due to the decrease in the indirect reduction zone.

This is caused by the expansion of low temperature zone in the upper shaft. Meanwhile, the level of $\eta_{\mathrm{co}}$ highly depends on the reducibility of sintered ore, as is obvious from this figure. Namely, from the transition of results every ten-days in November, it is understood that a lowering of the fuel rate was barely achieved without a decrease in the shaft gas efficiency by means of an improvement in the reducibility of sintered ore.

The process of reduction reaction was examined with the aid of three-interfaces unreacted core model ${ }^{8)}$ based on the actually measured temperature profile in the furnace. In the calculation, referring to both the results of JIS method reduction tests and many data brought by the vertical probes, the reaction rate parameters indicated in Table 3 were adopted. The values for conventional sintered ore were applied to the fuel rates of $452 \mathrm{~kg} / \mathrm{T}$ and $445 \mathrm{~kg} / \mathrm{T}$, while the values for the high reducibility sintered ore were applied to that of $392 \mathrm{~kg} / \mathrm{T}$ operation. Calculated results are shown in Fig. 6 which the observed values of gas composition.

At the low fuel rate of $392 \mathrm{~kg} / \mathrm{T}$, the reduction reaction occurs continuously from $\mathrm{Fe}_{2} \mathrm{O}_{3}$ to $\mathrm{FeO}$ via
$\mathrm{Fe}_{3} \mathrm{O}_{4}$ within the range where goes up form 1st reserve zone drastically, and it is noticeable that the reduction continues with a change of equilibrium gas composition of $\mathrm{FeO} / \mathrm{Fe}$ and the reduction degree reached above $60 \%$ at $1000{ }^{\circ} \mathrm{C}$. Namely, as for the characteristics of sintered ore which is required at great significance: both the reactions from $\mathrm{Fe}_{2} \mathrm{O}_{3}$ to $\mathrm{Fe}_{3} \mathrm{O}_{4}$ and from $\mathrm{Fe}_{3} \mathrm{O}_{4}$ to $\mathrm{FeO}$ should tend to occur in parallel at a low temperature zone, and in addition the rate of reduction from $\mathrm{FeO}$ to $\mathrm{Fe}$ should be high.

\section{Shape of Cohesive Zone and Stability of Burden Descent \\ 1. Shape of Cohesive Zone}

Measurement of the level and shape of cohesive zone was executed by using a feeding-type vertical probe $^{9)}$ and TDR system. ${ }^{10)}$ Some of the representative results are given in Figs. 7 and 8.

The values at the central part are plotted as if the probe were descending vertically into the dead-man.

The level of the cohesive zone lowered along with a reduction of fuel rate. Around the furnace wall, the lowering of the cohesive zone level stopped at a fuel rate of around $420 \sim 430 \mathrm{~kg} / \mathrm{T}$, whereas at the central part it continued to descend and reached the top of the dead-man where the temperature remained at around $1000^{\circ} \mathrm{C}$.

As indicated in an example brought by the measurement of TDR in Fig. 8 at a fuel rate of $404 \mathrm{~kg} / \mathrm{T}$, when the TDR cable reached the top of the dead-man, a waving pattern of continuous shortening by its fusion was scarcely observed and only the intermittent disconnection occurred.

Figure 9 shows some examples of the results brought by a luminous meter installed at the tuyere. At the

Table 3. Reduction rate parameter for calculation of reduction behavior.

\begin{tabular}{c|l|c|c}
\hline & & For normal sinter & For high reducibility sinter \\
\hline $\begin{array}{c}\text { Chemical reaction } \\
\text { rate constant } \\
(\mathrm{cm} / \mathrm{sec})\end{array}$ & $K_{\mathrm{Fe}_{3} \mathrm{O}_{4}}^{\mathrm{co}} \rightarrow \mathrm{FeO}$ & $1.36 \times 10^{5} \exp (-27400 / R T)$ & $1.86 \times 10^{5} \exp (-27400 / R T)$ \\
\hline \multirow{2}{R}{ Rabilins factor $(-)$} & $K_{\mathrm{FeO}}^{\mathrm{CO}} \rightarrow \mathrm{Fe}$ & $2.549 \times 10^{4} \exp (-29910 / R T)$ & $3.536 \times 10^{4} \exp (-29910 / R T)$ \\
& $\xi \mathrm{FeO}$ & 0.17 & 0.17 \\
\hline $\mathrm{Fe}$ & 0.07 & 0.12 \\
\hline
\end{tabular}

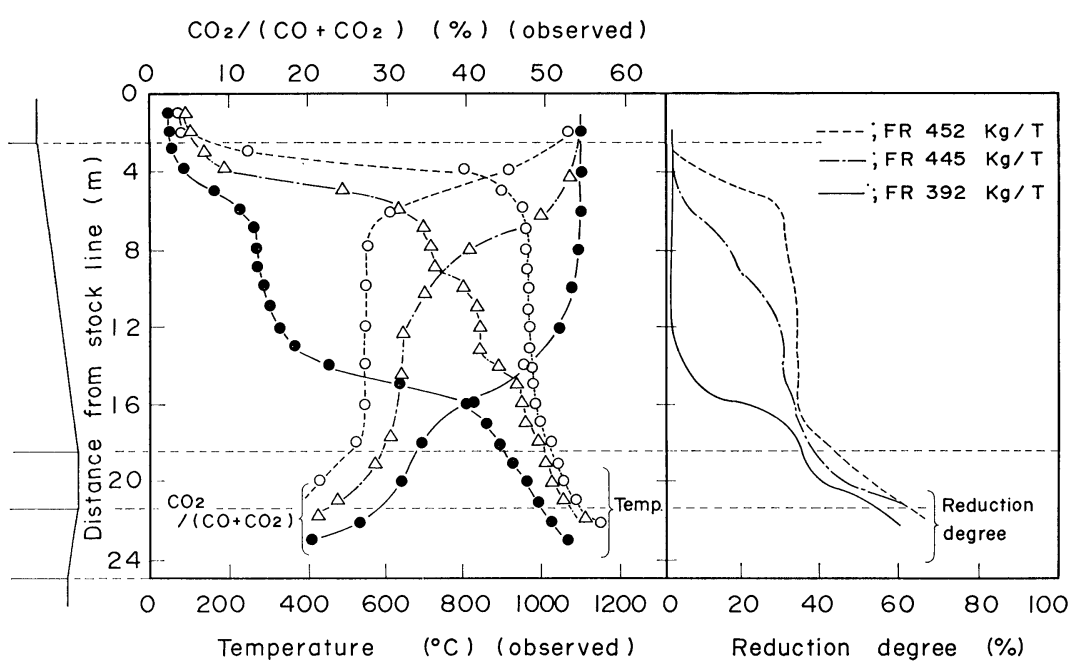

Fig. 6. Transition of observed temperature, gas composition and calculated reduction degree. 
low fuel rate, a cyclic movement of luminosity was observed almost corresponding with the charging cycle from the furnace top. This indicates that the fusing level of ore layers was very close to the raceway.

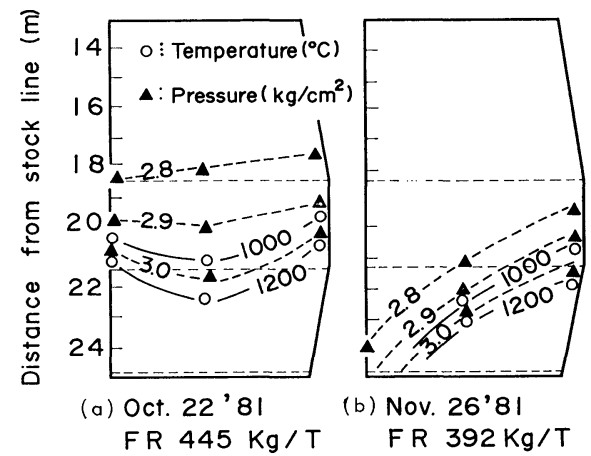

Fig. 7. Observed temperature and pressure distribution at lower part of the furnace.
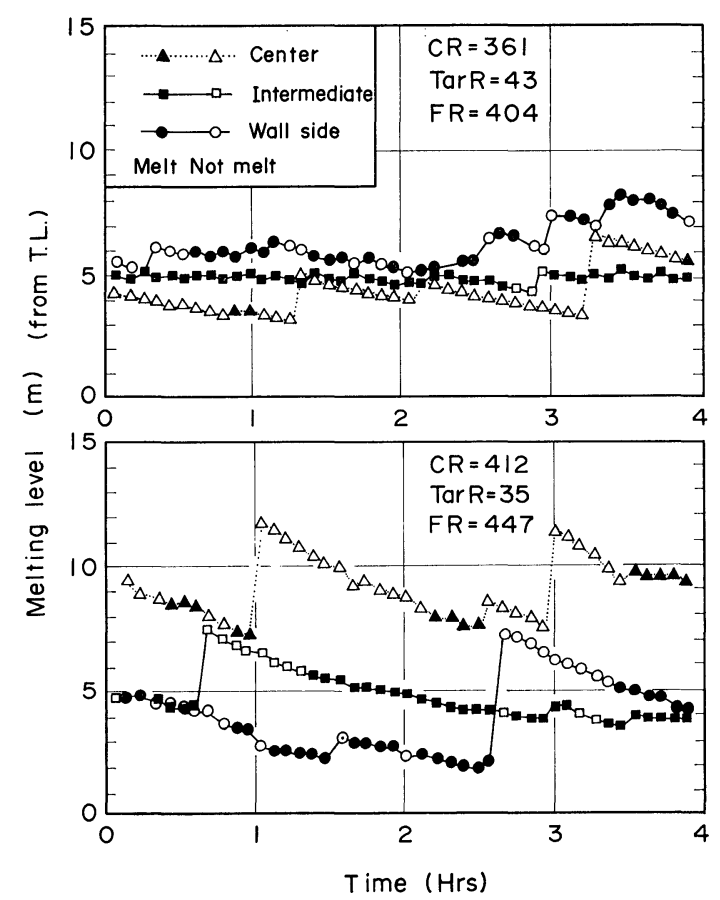

Fig. 8. Behavior of melting level measured by T.D.R. cohesive zone sensor.
And considering the stability of burden descending which will be mentioned in the next section, the schematic structure at the lower part of a furnace can be represented as in Fig. 10.

When the fuel rate reached around $400 \mathrm{~kg} / \mathrm{T}$, the vertical probe fed to the central portion did not detect the rise in both temperature and pressure (Figs. 4 (b) and $7(b))$, after reaching the level where the top of dead-man was considered to be located. So it is assumed that there was no fusion layer in that portion, that is, a "V" shaped cohesive zone was formed from the intermediate portion along the top surface of dead-man toward the furnace wall. In this situation, the mixture of coke and ore which is produced along the sliding surface would prevent the gas from ascending in this zone.

\section{Stability of Burden Descent}

When the fuel rate dropped to the level of 440 $430 \mathrm{~kg} / \mathrm{T}$, a phenomenon of the unstable descent of charges was observed. But when the fuel rate dropped furthermore, slips could not be detected and stable furnace conditions were achieved.

The mean level of cohesive zone, which was measured by both a feeding-type vertical probe and TDR system, is indexed as in Fig. 11. The period when slips appear most, corresponds to the transition period when the shape of cohesive zone was changing from " inverse $\mathrm{V}$ " to "V" via " $\mathrm{W}$ " shape.

The transitive change in the level and shape of the cohesive zone at this period was observed with lots of small fluctuations accompanying cable disconnections at the example at the fuel rate of $447 \mathrm{~kg} / \mathrm{T}$, (mentioned in Fig. 8), and its stability was worse than at the lower fuel rate.

That is, in the event of the "W" shape cohesive zone shown in Fig. 10, gas ascending from the raceway tended to flow to the center and the furnace wall, and the distribution of gas seems to change easily.

However, when the shape became "V", the gas flowed successively from the side of the furnace wall to the central side through the coke slit, so fluctuations would not happen. And ores around the center were not coherent and in the process where it slips over the top surface of the dead-man and descends,
Fig. 9.

Comparison of the results measured by the luminous meter at the tuyere.

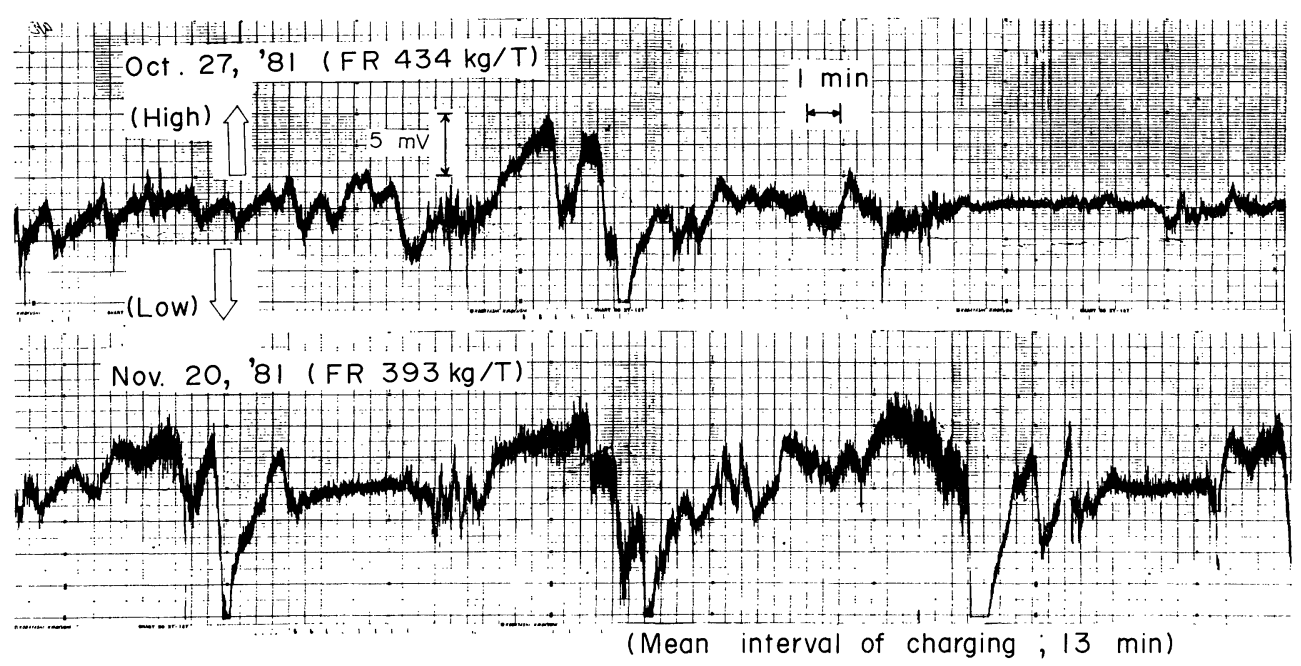




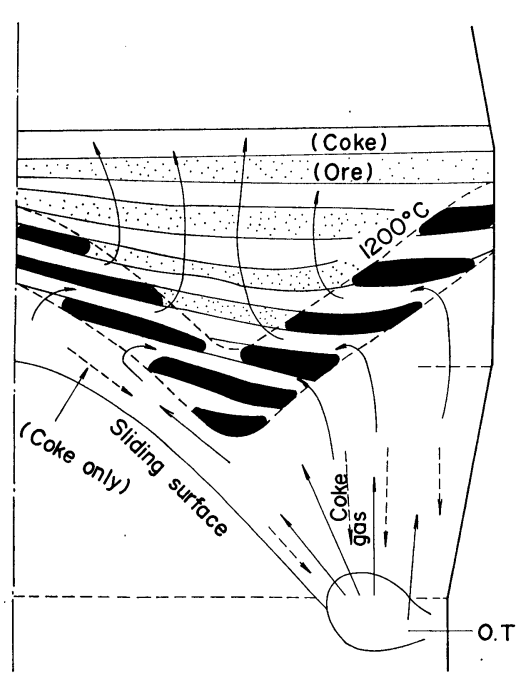

(a)

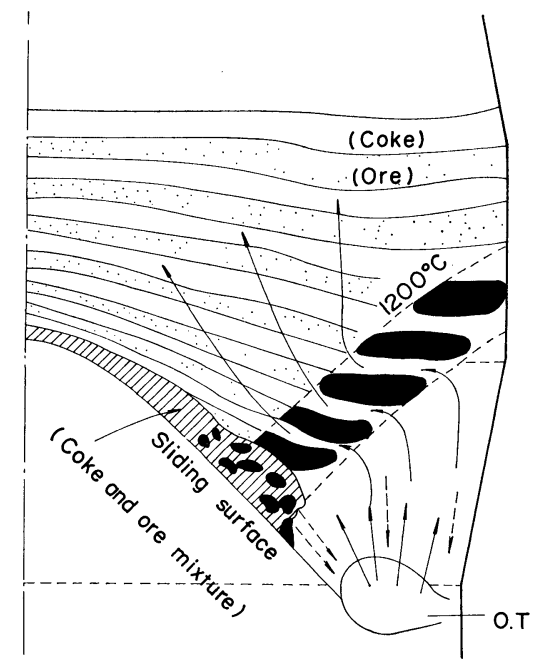

(b)

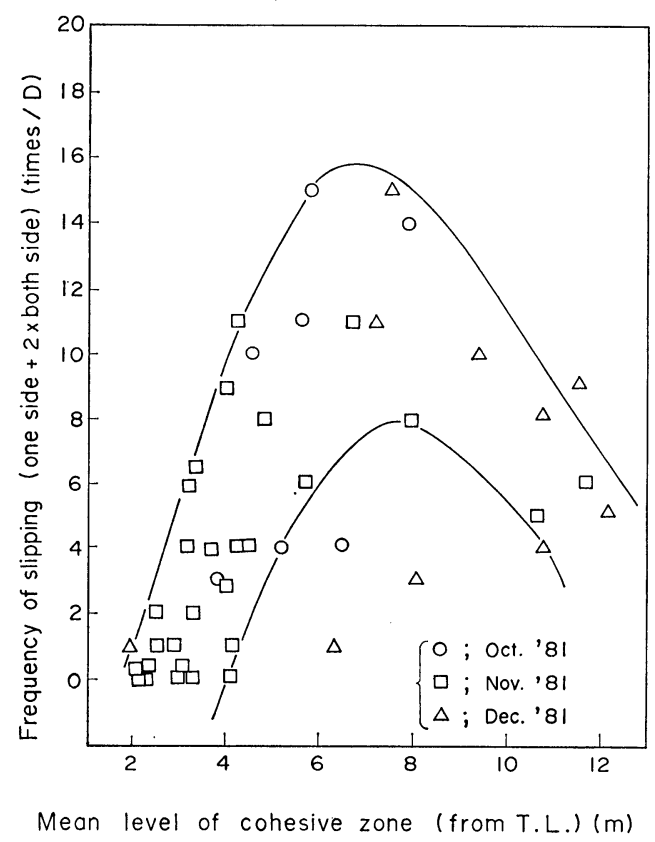

Fig. 11. Relation between frequency of slippings and melting level.

a mixing of ore and coke is thought to have taken place without forming a big cohesive block and to have fused right on the raceway. As a result, it is presumed to have led the stable furnace condition.

\section{Composition of Hot Metal}

In reducing the fuel rate, a low temperature of hot metal was aimed at as well, so that $\mathrm{Si}$ and $\mathrm{Mn}$ contents in hot metal decreased and S content increased. And $\mathrm{FeO}$ content in the slag obviously increased. These results are indicated in Fig. 12 in the relationship between the ratio of $L_{x} / L_{x}^{0}$ (the ratio of actual distribution to equilibrium distribution), and $\mathrm{FeO}$ content in slag.

In the calculation, hot metal temperature was substituted for the temperature in the hearth, according to the method proposed by Tsuchiya and others. ${ }^{11}$

With an increase in $\mathrm{FeO}$ content in slag, $L_{\mathrm{S}} / L_{\mathrm{S}}^{0}$ and (a) Ordinary operation (FR $465 \mathrm{~kg} / \mathrm{T}$ )

(b) Low fuel rate operation (FR 396 $\mathrm{kg} / \mathrm{T}$ )

Fig. 10. Estimated structure in the furnace.

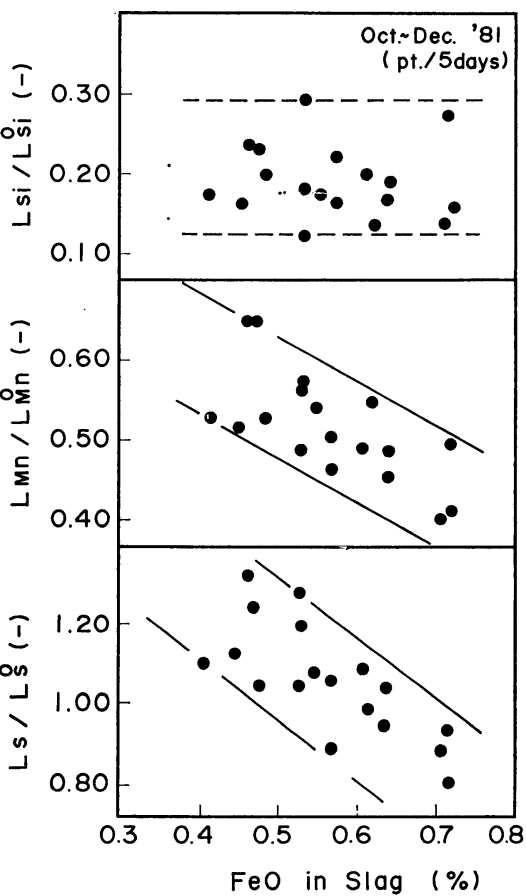

Fig. 12. Relation between the actua ldistribution ratio to the equilibrium of $\mathrm{Si}, \mathrm{Mn}, \mathrm{S}$ and $\mathrm{FeO}$ in slag.

$L_{\mathrm{Mn}} / L_{\mathrm{Mn}}^{0}$ become small. So it is presumed to be affected by an increase in the oxygen partial pressure at the furnace hearth. On the other hand, $L_{\mathrm{Si}} / L_{\mathrm{S} 1}^{0}$ does not show any distinctive correlation with $\mathrm{FeO}$ content in slag. Considering the above, the transfer other than slag-metal reaction, that is, $\mathrm{Si}$ transfer towards metal drops through $\mathrm{SiO}$ gas at the bosh is thought to have been restricted by a substantial reduction of the metal dropping zone.

\section{Factors Which Restrict the Low Fuel Rate Operation}

According to experiences from the test operation, in order to get the further low fuel rate or achieve a stable low fuel rate operation over a long period in future, several points to be noticed will be discussed hereafter. 
Table 4. Essential hindrance and countermeasures for the further low fuel rate.

\begin{tabular}{l|cc}
\hline \multirow{2}{*}{ Countermeasures } & \multicolumn{2}{|c}{ Essential hindrance } \\
\cline { 2 - 3 } & $\begin{array}{l}\text { 1. Reduction de- } \\
\text { gree attained } \\
\text { before the } \\
\text { fusion }\end{array}$ & $\begin{array}{c}\text { 2. Melting ability } \\
\text { for the } \\
\text { cohesive-layer }\end{array}$ \\
\hline $\begin{array}{l}\text { Reducibility of ore } \\
\text { Reactivity of coke }\end{array}$ & 0 & - \\
Slag amount & 0 & - \\
Flame temperature & 0 & 0 \\
\hline
\end{tabular}

Factors which restricted essentially the lower fuel rate in the test operation are as follows; the most severe restriction was the difficulty on the steel-making shops caused by both a low temperature of hot metal and a decline in desulfurization degree; and in addition, troubles in the dust-catcher caused by a condensation of water when top gas temperature dropped excessively and the significant increase of casting work load should be improved in view of a long term low fuel rate operation.

On the other hand, looking at the essential aspects of the blast furnace process, the problem of gas permeability which was an item for concern prior to the test operation will be negligible if the burden characteristics are maintained as well as in this test operation, considering the facts that the gas velocity slowed down in the furnace and cohesive zone was maintained in a stable " $\mathrm{V}$ " shape. However, it is predicted that the factors shown in Table 4 arising from an excessive rise in the heat flux ratio will be the largest hindrance in future, that is, one reduction stagnated and unreduced ore was carried down at the furnace hearth.

Secondly, a drastic lowering in the melt-down level caused a decline in the capacity to fuse ore layers around the raceway. All of these are very significant subjects because they endanger the stable furnace operation itself. As countermeasures against these crucial problems, it is necessary to develop a new technique to produce a sintered ore which has a high reduction rate in a small area of high temperature at the lower part of furnace. At the same time, it is desired to produce coke, with a sufficient strength, which reacts with $\mathrm{CO}_{2}$ at a lower temperature level in order to raise the reducing potential of gas ascending in this zone.

So as to improve the fusing capacity around the raceway, the slag amount should be reduced and the flame temperature as an intensity factor in heat exchange should be raised by some means, which leads to the effective radiant heating.

\section{Conclusion}

In order to clarify the various phenomena in a blast furnace and the various problems concerning its operation at an extremely low fuel rate, N.K.K. carried out the test operation in No. 3 Blast Furnace (inner volume; $3223 \mathrm{~m}^{3}$, blow in; Jan. 1975) at Fukuyama Works and the following results were obtained.

(1) A monthly mean fuel rate of $396 \mathrm{~kg} / \mathrm{T}$ was recorded in November 1981. The main factor contributing to the result was a substantial reduction of necessary heat at the lower part of the furnace.

(2) According to the results measured by a feeding-type vertical probe, it is recognized that the high temperature thermal reserve zone disappeared with a reduction in a fuel rate, and other reserve zones tended to appear at the lower temperature levels and the stagnation of ore reduction occurred at the shaft.

(3) According to the results measured by vertical proves, T.D.R. system and luminous meter at the tuyere, the shape of cohesive zone changed from "W" to "V" with a reduction in the fuel rate and it approached the raceway.

(4) In spite of a high ore/coke ratio and flat gas distribution pattern, pressure loss through the furnace decreased and a stable burden descent could be attained. The above is assumed because of the facts that both the velocity of ascending gas declined due to the drop in temperature and the shape of cohesive zone was maintained in the stable "V" shape, which enabled the gas flow to become stable.

(5) The decrease in $\mathrm{Si}$ content is considered as the result mainly of a shortening of the time for its transfer, with a lowering in the melt-down level. And the decrease of $\mathrm{Mn}$ and increase of $\mathrm{S}$ correspond to the increase of $\mathrm{FeO}$ in the slag, which seems to be governed by the equilibrium of slag-metal reaction.

(6) The essential problems to be solved for achieving the further low fuel rate in future should be a higher reducibility of ore in a smaller effective zone and a sufficient heat exchange capacity to fuse ore layers around the raceway.

\section{REFERENCES}

1) K. Okumura, T. Kawai, H. Marushima, H. Takahashi and J. Kurihara: Tetsu-to-Hagané, 66 (1980), 1956.

2) Y. Togino, M. Tateoka, M. Sugata, K. Yamaguchi, S. Kume and K. Yamaguchi: Tetsu-to-Hagané, 65 (1979), 1553.

3) M. Iizuka, S. Kishimoto, T. Shibuya and T. Fukushima: Tetsu-to-Hagané, 66 (1980), 1966.

4) M. Kase, M. Sugata, K. Okuda, Y. Umezu, S. Amano, H. Ono and C. Mizuuchi: Tetsu-to-Hagané, 67 (1981), S82.

5) A. Suzawa, Y. Okuno, T. Imai, T. Deno, S. Suzuki and E. Chikamatsu: Tetsu-to-Hagané, 67 (1981), S84.

6) S. Kajikawa, K. Tsutsumi, K. Tanaka, O. Komatsu, M. Hamaya, K. Kitajima and H. Kawata: Tetsu-to-Hagané, 68 (1982), S57.

7) Y. Ohno, Y. Yamada, K. Kondo, Y. Niwa, T. Sumigama and K. Kimura: Tetsu-to-Hagané, 67 (1981), S71.

8) T. Murayama, Y. Ono and Y. Kawai: Tetsu-to-Hagané, 63 (1977), 1229.

9) S. Kajikawa, K. Wakimoto, K. Niiya and T. Ishii: Tetsuto-Hagané, 66 (1980), S38.

10) T. Fukushima, S. Saito, T. Kobayashi, T. Shibuya, T. Furukawa and A. Yamaguchi: Tetsu-to-Hagané, 67 (1981), S69.

11) N. Tsuchiya, S. Taguchi, N. Takada and K. Okabe: Tetsu-to-Hagané, 63 (1977), 1791. 